\title{
A Comparative Study of the $\mathbf{A A}^{\prime} \mathbf{A}^{\prime \prime} \mathbf{A}^{\prime \prime} \mathbf{X}_{\mathrm{n}} \mathbf{X}_{\mathrm{n}}{ }^{\prime}$ and $\mathbf{A A}^{\prime} \mathbf{B B}^{\prime} \mathbf{X}_{\mathrm{n}} \mathbf{X}_{\mathrm{n}}{ }^{\prime}$ Spin Systems for $n=1,2$ and 3
}

\author{
DAGFINN W. AKSNES
}

Chemical Institute, University of Bergen, N-5000 Bergen, Norway

The combined composite particle-symmetry good quantum number approach has been used to achieve maximum factorization of the secular matrices of the $\mathrm{AA}^{\prime} \mathrm{A}^{\prime \prime} \mathrm{A}^{\prime \prime} \mathrm{X}_{\mathrm{n}} \mathrm{X}_{\mathrm{n}}$ ' and $\mathrm{AA}^{\prime} \mathrm{BB}^{\prime}$ $\mathrm{X}_{\mathrm{n}} \mathrm{X}_{\mathrm{n}}^{\prime}$ systems. The basic molecular wave functions of the composite particle spin states have been classified under the highest possible symmetry. The next step involves the evaluation of the matrix elements in terms of the chemical shifts and coupling constants.

Rather than calculating the transition frequencies directly familiar sub-spectra from which the spectral parameters can be obtained, have been picked out. It is shown that the $\mathrm{AA}^{\prime} \mathrm{BB}^{\prime}$ region of the $\mathrm{AA}^{\prime} \mathrm{BB}^{\prime} \mathrm{X}_{\mathbf{n}} \mathrm{X}_{\mathbf{n}}{ }^{\prime}$ system can be completely broken down into $(n+1)$ different $a a^{\prime} b^{\prime} b^{\prime}$ sub-spectra and $\sum_{i=1}^{n} i$ different abcd sub-spectra when $J_{\mathbf{x x}^{\prime}}=0$. For the $\mathrm{AA}^{\prime} \mathbf{A A}^{\prime \prime}$. $\mathrm{A}^{\prime \prime \prime} \mathrm{X}_{\mathrm{n}} \mathrm{X}_{\mathrm{n}}^{\prime}$ system these sub-spectra simplify into $a_{4}$ and $a a^{\prime} b^{\prime} b^{\prime}$ sub-spectra, respectively. The spectral transformations of the contributing subspectra have been worked out. When $J_{\mathrm{xx}^{\prime}} \neq 0$, however, only sub-patterns characterized by the extreme values of $m\left(X_{q}\right)$ within a given sub. system, give rise to real sub-spectra.

The experimental $100 \mathrm{MHz}$ spectra of 1,4dibromobutane and trans,trans-2,4-hexadiene and the $270 \mathrm{MHz}$ spectrum of butane are shown as typical examples of the studied spin systems.

NMR spectra of the general types $\mathrm{AA}^{\prime} \mathrm{A}^{\prime \prime} \mathrm{A}^{\prime \prime \prime}$. $\mathrm{X}_{\mathrm{n}} \mathrm{X}_{\mathrm{n}}{ }^{\prime}$ and $\mathrm{AA}^{\prime} \mathrm{BB}^{\prime} \mathrm{X}_{\mathrm{n}} \mathrm{X}_{\mathrm{n}}{ }^{\prime}$ have, apart from the $\mathrm{AA}^{\prime} \mathrm{A}^{\prime \prime} \mathrm{A}^{\prime \prime} \mathrm{XX}^{\prime}$ system, received little attention. However, the combined symmetry-composite particle-good quantum number approach makes it feasible to tackle spectra of such large spin systems. ${ }^{1}$

The $\mathrm{AA}^{\prime} \mathrm{A}^{\prime \prime} \mathrm{A}^{\prime \prime} \mathrm{X}_{3} \mathrm{X}_{3}{ }^{\prime}$ system has similar features as the $\mathrm{AA}^{\prime} \mathrm{A}^{\prime \prime} \mathrm{A}^{\prime \prime} \mathrm{XX}^{\prime}$ system which has been studied by Diehl, ${ }^{2}$ Lynden-Bell, ${ }^{3}$ and by Kaiser. ${ }^{15}$ The algebraic manipulations are more

Acta Chem. Scand. A 28 (1974) No. 4 complex, however, due to the four possible spin combinations and increasing dimension of the secular matrices. Jones ${ }^{4}$ has shown that the use of the permutation symmetry groups for the non-rigid $\mathrm{AA}^{\prime} \mathrm{A}^{\prime \prime} \mathrm{A}^{\prime \prime} \mathrm{X}_{2} \mathrm{X}_{2}{ }^{\prime}$ system leads to identical factorization of the Hamiltonian matrix as does the composite particle method, as expected. The calculations are, however, much simpler using the latter.

The nuclear arrangement $\mathrm{AA}^{\prime} \mathrm{A}^{\prime \prime} \mathrm{A}^{\prime \prime} \mathrm{X}_{\mathrm{n}} \mathrm{X}_{\mathbf{n}}{ }^{\prime}$ of $C_{2 \mathrm{v}} \quad\left(C_{2 \mathrm{~h}}\right)$ symmetry is often found, for instance, in 1,4-difluorobenzene $(n=1), 1,4$-dibromobutane $(n=2), 5$ perfluorobutane $(n=3)$, and perfluoro $p$-xylene $(\mathrm{n}=3) .^{6}$ The $\mathrm{AA}^{\prime} \mathrm{BB}^{\prime}$ $\mathrm{X}_{\mathrm{n}} \mathrm{X}_{\mathrm{n}}^{\prime}$ spin system of $C_{2}$ symmetry can be typified by 1,2-difluorobenzene $(n=1), \alpha, \alpha^{\prime}$ dichloro-o-xylene $(\mathrm{n}=2)$, cis,cis-2,4-hexadiene $(n=3)$ and trans-trans-2,4-hexadiene $(n=3))^{7}$

The experimental $100 \mathrm{MHz}$ spectra of 1,4dibromobutane and trans,trans-2,4-hexadiene and the $270 \mathrm{MHz}$ spectrum of butane will be shown as typical examples of the studied spin systems.

\section{FACTORIZATION OF THE HAMILTONIAN}

Composite particle notation. It is convenient to define the group magnetic quantum numbers

$$
\begin{aligned}
& m\left(A_{4}\right)=m_{A}+m_{A^{\prime}}+m_{A^{\prime}}+m_{A^{\prime \prime \prime}} \\
& m\left(A_{2} B_{2}\right)=m_{A}+m_{A^{\prime}}+m_{B}+m_{B^{\prime}} \\
& m\left(X_{q}\right)=m_{X}+m_{X^{\prime}} ; q=2 n
\end{aligned}
$$

and the total quantum number

$$
m_{T}=m\left(A_{4}\right)\left[\text { or } m\left(A_{2} B_{2}\right)\right]+m\left(X_{q}\right)
$$

$$
\text { The } \mathrm{AA}^{\prime} \mathrm{A}^{\prime \prime} \mathrm{A}^{\prime \prime} \mathrm{X}_{\mathrm{n}} \mathrm{X}_{\mathrm{n}}{ }^{\prime} \text { and } \mathrm{AA}^{\prime} \mathrm{BB}^{\prime} \mathrm{X}_{\mathrm{n}} \mathrm{X}_{\mathbf{n}}{ }^{\prime}
$$


spin systems for $n=2$ and 3 have each four overall spin states: ${ }^{1}$

\section{DDDD $A A$ \\ $\operatorname{DDDD} A B \quad \operatorname{DDDD} B A$ \\ $\mathrm{DDDDBB}$}

where the composite particles $A=\mathrm{T}$ or $\mathrm{Q}$ and $B=\mathrm{S}$ or $\mathrm{D}$ for $\mathrm{n}=2$ or 3 , respectively. The degeneracy of the $\mathrm{D}$ particles of the $\mathrm{X}_{3} \mathrm{X}_{3}{ }^{\prime}$ nuclei is 2 whereas the remaining particles have a degeneracy of 1 . When $n=2$ the total relative intensities (normalized to $\mathrm{n} \times 2^{\mathbf{n - 1}}$ for an $\mathrm{n}$-spin system) ${ }^{1}$ attributable to these four spin states are $672,160,160$, and 32 . Listed in the same order the four strongly coupled nuclei contribute 288, 96, 96, and 32 intensity units. Similarly, when $n=3$ the DDDDQQ, DDDDQD, DDDDDQ and DDDDDD spin states contribute altogether $1792,1280,1280$, and 768 intensity units. Now, the four strongly coupled nuclei give rise to 512 intensity units for each spin state.

Basic symmetry wave functions. The DDDD $A B$ and DDDDBA spin states are degenerate and do not mix. It is thus sufficient to treat only one of these states, say DDDD $A B$. The secular matrices of the three different overall spin states can be factorized in accordance with symmetry. The DDDD $A A$ and $\mathrm{DDDD} B B$ states of the $\mathrm{AA}^{\prime} \mathrm{A}^{\prime \prime} \mathrm{A}^{\prime \prime} \mathrm{X}_{\mathrm{n}} \mathrm{X}_{\mathrm{n}}{ }^{\prime}$ and $\mathrm{AA}^{\prime} \mathrm{BB}^{\prime} \mathrm{X}_{\mathrm{n}} \mathbf{X}_{\mathrm{n}}{ }^{\prime}$ systems possess $C_{2 v}\left(C_{2 h}\right)$ and $C_{2}$ symmetry, respectively. The DDDD $A B$ spin state of the former spin system possesses $C_{2}$ symmetry.
The four A nuclei have previously been classified according to the symmetry species $A_{1}$, $A_{2}, B_{1}$, and $B_{2}$ of the $C_{2 v}$ point group., ${ }^{3,9}$ The symmetrized spin functions $\phi_{1} \Gamma \mu\left(\mathrm{A}_{2} \mathrm{~B}_{2}\right)$ of the $\mathrm{AA}^{\prime} \mathrm{BB}^{\prime}$ nuclei are listed in Ref. 8, p. 400.

The QQ, TT, and DD functions $\psi_{\mathrm{j}} \Gamma_{\nu}\left(\mathrm{X}_{\mathrm{q}}\right)$ of the $\mathbf{X}_{\mathbf{n}} \mathbf{X}_{\mathbf{n}}{ }^{\prime}$ nuclei have also been classified according to symmetry as shown in Table 1 for the $Q Q$ functions.

The basic molecular wave functions $\Phi_{k} \Gamma \lambda$ $\left(A_{4} X_{q}\right)$ can be constructed from the basic group symmetry wave functions (Table 1) by taking all possible products $\phi_{\mathrm{i}} \Gamma \mu\left(\mathrm{A}_{4}\right) \times \psi_{\mathrm{j}} \Gamma \boldsymbol{\nu}\left(\mathrm{X}_{\mathrm{q}}\right)=$ $\Phi_{\mathbf{k}} \Gamma \lambda\left(\mathrm{A}_{\mathbf{4}} \mathrm{X}_{\mathrm{q}}\right)$ and reclassifying these product functions under the total molecular symmetry. The $\Phi_{\mathbf{r}} \Gamma \lambda\left(\mathrm{A}_{2} \mathrm{~B}_{2} \mathrm{X}_{\mathrm{q}}\right)$ functions can be obtained by a similar procedure.

Table 2 shows a schematic energy level diagram for the DDDD $A A$ spin states $(A=\mathrm{Q}$, $\mathrm{T}, \mathrm{D}, \mathrm{S})$ of the general $\mathrm{AA}^{\prime} \mathrm{A}^{\prime \prime} \mathrm{A}^{\prime \prime \prime} \mathrm{X}_{\mathrm{n}} \mathrm{X}_{\mathrm{n}}$ ' system. It is also readily shown that the DDDDST spin state of $C_{2}$ symmetry forms 1:2:4:2:1 $(A)+$ 2:2:2(B) energy level groupings for $\mathrm{m}\left(\mathrm{X}_{4}\right)= \pm 1$ and 0 . The DDDDQD spin state of $C_{2}$ symmetry can similarly be factorized into $1: 2: 4: 2: 1(A)+$ 2:2:2(B) and 2:4:8:4:2(A) +4:4:4(B) energy level groupings for $m\left(X_{6}\right)= \pm 2$ and $0, \pm 1$, respectively. When $J_{\mathbf{X x}}=0$, however, the two latter sub-patterns can be further reduced into two sets of $1: 2: 4: 2: 1(A)+2: 2: 2(B)$ energy levels. A schematic diagram over the factorization of the secular matrices of the $\mathrm{AA}^{\prime} \mathbf{B B}^{\prime} \mathbf{X}_{n} \mathrm{X}_{n}{ }^{\prime}$ system is easily obtained by adding together correspond-

Table 1. Basic $\mathrm{QQ}$ symmetry wave functions for the $\mathrm{X}_{3} \mathrm{X}_{3}{ }^{\prime}$ nuclei classified according to $C_{2}$ symmetry. The diagonal and non-zero off-diagonal elements of $\mathscr{H}\left(\mathrm{X}_{6}\right)$ are also listed.

\begin{tabular}{|c|c|c|c|c|c|}
\hline State & $\mathrm{m}\left(\mathbf{X}_{8}\right)$ & $\begin{array}{l}\text { Symmetry } \\
\text { species } \Gamma_{\nu}\end{array}$ & $\Psi_{\mathrm{j}}^{\Gamma_{\nu}}\left(\mathrm{X}_{6}\right)$ & $H\left(\mathrm{X}_{6}\right)_{\mathrm{jj}}{ }^{a}$ & $H\left(\mathrm{X}_{6}\right)_{\mathrm{jj}^{\prime}}{ }^{b}$ \\
\hline $\begin{array}{r}1 \\
2 \\
3 \\
4 \\
5 \\
6 \\
7 \\
7 \\
8 \\
9 \\
10\end{array}$ & $\begin{array}{l}\mathbf{3} \\
\mathbf{2} \\
\mathbf{1}\end{array}$ & $\begin{array}{l}A \\
A \\
B \\
A^{11} \\
A^{12} \\
B \\
A^{01} \\
A^{02} \\
B^{01} \\
B^{02}\end{array}$ & $\begin{array}{l}Q^{3 / 2} Q^{3 / 2} \\
2^{-1 / 2}\left(Q^{3 / 2} Q^{1 / 2}+Q^{1 / 2} Q^{3 / 2}\right) \\
2^{-1 / 2}\left(Q^{3 / 2} Q^{1 / 2}-Q^{1 / 2} Q^{3 / 2}\right) \\
2^{-1 / 2}\left(Q^{3 / 2} Q^{-1 / 2}+Q^{-1 / 2} Q^{3 / 2}\right) \\
Q^{1 / 2} Q^{1 / 2} \\
2^{-1 / 2}\left(Q^{3 / 2} Q^{-1 / 2}-Q^{-1 / 2} Q^{3 / 2}\right) \\
2^{-1 / 2}\left(Q^{3 / 2} Q^{-3 / 2}+Q^{-3 / 2} Q^{3 / 2}\right) \\
2^{-1 / 2}\left(Q^{1 / 2} Q^{-1 / 2}+Q^{-1 / 2} Q^{1 / 2}\right) \\
2^{-1 / 2}\left(Q^{3 / 2} Q^{-3 / 2}-Q^{-3 / 2} Q^{3 / 2}\right) \\
2^{-1 / 2}\left(Q^{1 / 2} Q^{-1 / 2}-Q^{-1 / 2} Q^{1 / 2}\right)\end{array}$ & $\begin{array}{r}3 v_{\mathrm{X}}+4 X \\
2 v_{\mathrm{X}}+4 X \\
2 v_{\mathrm{X}}-2 X \\
v_{\mathrm{X}}-2 X \\
v_{\mathrm{X}} \\
v_{\mathrm{X}}-2 X \\
-5 X \\
+3 X \\
\quad-5 X \\
-9 X\end{array}$ & $\begin{array}{l}H_{45}=2 \sqrt{6 X} \\
H_{78}=3 X \\
H_{910}=3 X\end{array}$ \\
\hline
\end{tabular}

a $1 / 2 X=\frac{1}{d} J_{\mathrm{XX}^{\prime}}$ has been subtracted from every diagonal element. ${ }^{b}$ For convenience the $\mathrm{X}_{6}$ index has been omitted in the expressions below. 
Table 2. Schematic diagram of the factorization of the composite particle spin states of the $\mathbf{A A}^{\prime} \mathbf{A}^{\prime \prime} \mathbf{A}^{\prime \prime} \mathbf{X}_{\mathbf{n}} \mathbf{X}_{\mathbf{n}}$ spin system using good quantum numbers and $C_{2 v}$ symmetry.

\begin{tabular}{lllll}
\hline & Symmetry species $^{a}$ & & \\
$A_{1}=A_{1} \times A_{1}$ & $A_{2}=A_{1} \times A_{2}$ & $B_{2}=A_{1} \times B_{2}$ & $B_{1}=A_{1} \times B_{1}$ \\
$\pm \mathrm{m}_{\mathrm{T}}^{b}$ & or $B_{2} \times B_{2}$ & or $B_{2} \times B_{1}$ & or $B_{2} \times A_{1}$ & or $B_{2} \times A_{2}$ \\
\hline
\end{tabular}

\begin{tabular}{|c|c|c|c|c|c|c|c|c|c|c|c|c|c|c|c|c|c|c|c|c|c|c|c|}
\hline$F+2$ & 1 & & & & & & & & & & & & & & & & & & & & & & \\
\hline$F+1$ & 1 & 1 & & & & & 1 & & & & & & 1 & 1 & & & & & 1 & & & & \\
\hline$F$ & $\mathbf{3}$ & 2 & 1 & 1 & & & 1 & 2 & & & & & 1 & 2 & 1 & & & & 1 & 2 & & & \\
\hline$F-1$ & 1 & 4 & 2 & 1 & 1 & 1 & 1 & 2 & 2 & 1 & & & 1 & 4 & 2 & 1 & 1 & 1 & 1 & 2 & 2 & 1 & \\
\hline$F-2$ & 1 & 2 & 4 & 3 & 2 & 2 & & 2 & 2 & 1 & 2 & 2 & & 2 & 4 & 1 & 2 & 2 & & 2 & 2 & 1 & 2 \\
\hline$F-2$ & & 1 & 2 & 1 & 4 & 4 & & & 2 & 1 & 2 & 2 & & 1 & 2 & 1 & 4 & 4 & & & 2 & 1 & 2 \\
\hline$F-4$ & & & 1 & 1 & 2 & 2 & & & & & 2 & 2 & & & 1 & & & 2 & & & & & 2 \\
\hline$F-5$ & & & & & & 1 & & & & & & & & & & & 1 & 1 & & & & & \\
\hline$\left|m\left(\mathbf{X}_{\mathbf{q}}\right)\right|^{c}$ & $F$ & $F-1$ & $F-$ & & $F-3$ & & $F$ & $F-1$ & $F-2$ & & $F-3$ & & $F$ & $F-1$ & $F-$ & & $F-3$ & 3 & $F$ & $F-1$ & $F-2$ & 2 & $F-3$ \\
\hline
\end{tabular}

a Two entries for a given value of $\mathrm{m}\left(\mathrm{X}_{\mathrm{q}}\right)$ indicate the additional factorization occurring when $J_{\mathrm{XX}}=0$. ${ }^{b} F=3,2,1$ and 0 for QQ, TT, DD and SS states, respectively. The factorization above is valid only for $\left|\mathrm{m}\left(\mathrm{X}_{\mathrm{q}}\right)\right| \geq 0$.

ing matrix dimensions under the $A_{1}, A_{2}$ and $B_{1}, B_{2}$ symmetry species (Table 2) or $A, B$ symmetry species as appropriate.

Calculation of matrix elements. The total spin Hamiltonian of the $\mathrm{AA}^{\prime} \mathbf{A}^{\prime \prime} \mathbf{A}^{\prime \prime} \mathrm{X}_{\mathrm{n}} \mathrm{X}_{\mathrm{n}}$ ' system can be written.

$$
\mathscr{H}=\mathscr{H}\left(\mathrm{A}_{\iota}\right)+\mathscr{H}\left(\mathrm{X}_{q}\right)+\mathscr{H}(\mathrm{AX})
$$

The first two terms on the right-hand side represent the $A$ and $X$ parts of the Hamiltonian whereas the final term takes account of coupling between these two groups of nuclei. The Hamil. tonian of the $\mathrm{AA}^{\prime} \mathrm{BB}^{\prime} \mathrm{X}_{\mathbf{n}} \mathrm{X}_{\mathbf{n}}{ }^{\prime}$ system can, of course, be written in a similar manner.

It is impracticable to tabulate the large number of matrix elements of the present spin systems. The diagonal and off-diagonal matrix elements for the DDDDQQ, DDDDTT, and DDDDDD sub-systems may, however, be obtained from eqns. (2) - (5).

$$
\begin{aligned}
& H\left(\mathrm{~A}_{4} \mathrm{x}_{\mathrm{q}}\right)_{\mathrm{kk}}=H\left(\mathrm{~A}_{4}\right)_{\mathrm{ii}}+H\left(\mathrm{X}_{\mathrm{q}}\right)_{\mathrm{jj}}+ \\
& \mathrm{m}\left(\mathrm{A}_{4}\right) \mathrm{m}\left(\mathrm{X}_{\mathrm{q}}\right) K_{\mathrm{A}} \\
& H\left(\mathrm{~A}_{4} \mathrm{X}_{\mathrm{q}}\right)_{\mathrm{kl}}=H\left(\mathrm{~A}_{4}\right)_{\mathrm{ii}^{\prime}}+H\left(\mathrm{X}_{\mathrm{q}}\right)_{\mathrm{jj}}+H(\mathrm{AX})_{\mathrm{kl}} \\
& H\left(\mathrm{~A}_{2} \mathrm{~B}_{2} \mathrm{X}_{\mathrm{q}}\right)_{\mathrm{kk}}=H\left(\mathrm{~A}_{2} \mathrm{~B}_{2}\right)_{\mathrm{ii}}+H\left(\mathrm{X}_{\mathrm{q}}\right)_{\mathrm{jj}}+ \\
& \mathrm{m}\left(\mathrm{A}_{2}\right) \mathrm{m}\left(\mathrm{X}_{\mathrm{q}}\right) K_{\mathrm{A}}+\mathrm{m}\left(\mathrm{B}_{2}\right) \mathrm{m}\left(\mathrm{X}_{\mathrm{q}}\right) K_{\mathrm{B}} \\
& H\left(\mathrm{~A}_{2} \mathrm{~B}_{2} \mathrm{X}_{\mathrm{q}}\right)_{\mathrm{kl}}=H\left(\mathrm{~A}_{2} \mathrm{~B}_{2}\right)_{\mathrm{ij}^{\prime}}+H\left(\mathrm{X}_{\mathrm{q}}\right)_{\mathrm{jj}}+ \\
& H(\mathrm{ABX})_{\mathrm{k} 1} \\
& \text { where } K_{\mathrm{i}}=\frac{1}{2}\left(J_{\mathrm{ix}}+J_{\mathrm{iX}}\right) \text { with } \mathrm{i}=\mathrm{A} \text { or B. }
\end{aligned}
$$

The first two terms in eqns. (2) $-(5)$ refer to the appropriate matrix elements of the basic Acta Chem. Scand. A 28 (1974) No. 4 groups. Some of these matrix elements are listed in Table 1 and in Refs. 3 and 8.

The last term in eqn. (3) is given by

$$
\begin{aligned}
& H(\mathrm{AX})_{\mathrm{k} 1}=\int \phi_{\mathrm{i}} \Gamma_{\mathrm{i}}\left(\mathrm{A}_{4}\right) \psi_{\mathrm{j}} \Gamma_{\mathrm{s}}\left(\mathrm{X}_{\mathrm{q}}\right) \mathscr{H}(\mathrm{AX}) \phi_{\mathrm{i}^{\prime}} \Gamma_{\mathrm{s}}\left(\mathrm{A}_{4}\right) \\
& \psi_{\mathrm{j}}, \Gamma_{\mathrm{s}}\left(\mathrm{X}_{\mathrm{q}}\right) \mathrm{d} \tau=\left[2-\mathrm{m}\left(\mathrm{A}_{4}\right)\right]\left[F-\mathrm{m}\left(\mathrm{X}_{\mathrm{q}}\right)\right] L_{\mathrm{A}}
\end{aligned}
$$

A corresponding expression is readily found for the last term in eqn. (5), viz.

$$
\begin{aligned}
& H(\mathrm{ABX})_{\mathrm{k} 1}=\left[1-\mathrm{m}\left(\mathrm{A}_{2}\right)\right]\left[F-\mathrm{m}\left(\mathrm{X}_{\mathrm{q}}\right)\right] L_{\mathrm{A}}+ \\
& {\left[1-\mathrm{m}\left(\mathrm{B}_{2}\right)\right]\left[F-\mathrm{m}\left(\mathrm{X}_{\mathrm{q}}\right)\right] L_{\mathrm{B}}}
\end{aligned}
$$

where $F=3,2$, and 1 for QQ, TT, and DD functions, respectively. $L_{\mathrm{i}}=\frac{1}{2}\left(J_{\mathrm{ix}}-J_{\mathrm{ix}}\right)$ with $\mathrm{i}=\mathrm{A}$ or $\mathbf{B}$. The off-diagonal elements given by eqns. (6) and (7) are non-zero only when the following conditions are fulfilled:

(1) $\Gamma_{1} \times \Gamma_{3}=\Gamma_{2} \times \Gamma_{4}=B_{2}$

(2) $\phi_{\mathrm{i}^{\prime}} \Gamma_{\mathrm{z}}\left(\mathrm{A}_{4}\right)$ and $\phi_{\mathrm{i}^{\prime}} \Gamma_{\mathrm{z}}\left(\mathrm{A}_{2} \mathrm{~B}_{2}\right)$ contain the same basic spin $\frac{1}{2}$ product wave functions as $\phi_{\mathrm{i}} \Gamma_{1}\left(\mathrm{~A}_{4}\right)$ and $\phi_{\mathrm{j}} \Gamma_{2}\left(\mathrm{~A}_{2} \mathrm{~B}_{2}\right)$, respectively. (3) $\psi_{\mathrm{j}} \Gamma_{\mathrm{t}}\left(\mathrm{X}_{\mathrm{q}}\right)$ contains the same $A \mathrm{mX} A \mathrm{~m}^{\prime}$ functions as $\psi_{\mathrm{j}} \Gamma_{\mathrm{z}}\left(\mathrm{X}_{\mathrm{q}}\right)$

The diagonal matrix elements for the DDDDQD and DDDDTS sub-states of $C_{2}$ symmetry follow from eqn. (8)

$$
\begin{aligned}
& H\left(\mathrm{~A}_{4} \mathrm{x}_{\mathrm{q}}\right)_{\mathrm{kk}}=H\left(\mathrm{~A}_{4}\right)_{\mathrm{ii}}+\mathrm{m}\left(\mathrm{X}_{\mathrm{q}}\right) v_{\mathrm{x}}+\mathrm{m}_{\mathrm{x}} \mathrm{m}_{\mathrm{x}^{\prime}} J_{\mathrm{xx}^{\prime}}+ \\
& \mathrm{m}\left(\mathrm{A}_{4}\right) \mathrm{m}\left(\mathrm{X}_{\mathrm{q}}\right) K_{\mathrm{A}}+\left(\mathrm{m}_{\mathrm{A}}+\mathrm{m}_{\mathrm{A}^{\prime \prime \prime}}-\mathrm{m}_{\mathrm{A}^{\prime}}-\mathrm{m}_{\mathrm{A}^{\prime \prime}}\right) \cdot \\
& \left(\mathrm{m}_{\mathrm{x}}-\mathrm{m}_{\mathrm{x}^{\prime}}\right) L_{\mathrm{A}}
\end{aligned}
$$

The only off-diagonal elements are the group 
values for the $A$ functions and $\frac{1}{2} \sqrt{3} J_{\mathrm{XX}}$ or $J_{\mathrm{XX}^{\prime}}$ for the QD functions.

It is only necessary to calculate matrix elements for positive values of $m\left(A_{4}\right), m\left(A_{2} B_{2}\right)$ and $m\left(X_{q}\right)$ since the remaining elements then follow from simple symmetry considerations.

Calculations of transition frequencies. The $\mathrm{A}$ and $\mathrm{X}$ transitions of the $\mathrm{AA}^{\prime} \mathrm{A}^{\prime \prime} \mathrm{A}^{\prime \prime} \mathrm{X}_{\mathrm{n}} \mathrm{X}_{\mathrm{n}}$ ' system are picked out in the ordinate and diagonal direction in Table 2 by using the selection rules $\Delta \mathrm{m}\left(\mathrm{A}_{4}\right)=1, \Delta \mathrm{m}\left(\mathrm{X}_{\mathrm{q}}\right)=0$ and $\Delta \mathrm{m}\left(\mathrm{A}_{\mathrm{4}}\right)=0, \Delta \mathrm{m}\left(\mathrm{X}_{\mathrm{q}}\right)=1$, respectively. Only transition frequencies corresponding to positive and zero values of $m\left(A_{4}\right)$ and $m\left(X_{q}\right)$ need to be calculated since the remaining lines are obtained by reflecting the whole pattern at the point $v_{\mathrm{A}}$ for the $\mathrm{A}$ spectrum and at $v_{\mathbf{X}}$ for the $\mathrm{X}$ spectrum. The transition frequencies of the $\mathrm{AA}^{\prime} \mathrm{BB}^{\prime} \mathrm{X}_{\mathbf{n}} \mathrm{X}_{\mathrm{n}}{ }^{\prime}$ system are found by a similar procedure.

Rather than calculating the transition frequencies directly it is often advantageous to pick out familiar sub-spectra from which the spectral parameters may be obtained.

\section{SUB-SPECTRAL TRANSFORMATIONS}

The $A$ and $B$ spectra. The use of symmetry and good quantum numbers show that for the extreme values of $\mathrm{m}\left(\mathrm{X}_{\mathrm{q}}\right)$ within the $\mathrm{DDDD} A A$ $(A=\mathrm{Q}, \mathrm{T}, \mathrm{D}, \mathrm{S}), \mathrm{DDDDQD}$ and DDDDST subsystems, there is break-down into $\mathrm{aa}^{\prime} \mathrm{bb}^{\prime}$ and abcd sub-spectra for the $\mathrm{AA}^{\prime} \mathrm{BB}^{\prime}$ part of the $\mathrm{AA}^{\prime} \mathrm{BB}^{\prime} \mathbf{X}_{\mathbf{n}} \mathbf{X}_{\mathbf{n}}^{\prime}$ system. These sub-spectra simplify into $a_{4}$ and $a a^{\prime} b b^{\prime}$ sub-spectra, respectively, for the $\mathrm{AA}^{\prime} \mathrm{A}^{\prime \prime} \mathrm{A}^{\prime \prime} \mathrm{X}_{\mathrm{n}} \mathrm{X}_{\mathrm{n}}{ }^{\prime}$ system (Table 2).

The spectral transformations for the subspectra characterized by the extreme values of $\mathbf{m}\left(X_{q}\right)$ within a given sub-system, have been worked out using the procedure due to Diehl:2*

$$
\begin{aligned}
& v_{\mathrm{a}}=v_{\mathrm{A}}+\mathrm{m}\left(\mathrm{X}_{\mathrm{q}}\right) K_{\mathrm{A}}-p L_{\mathrm{A}} ; v_{\mathrm{b}}=v_{\mathrm{B}}+ \\
& \mathrm{m}\left(\mathrm{X}_{\mathrm{q}}\right) K_{\mathrm{B}}-p L_{\mathrm{B}} \\
& v_{\mathrm{c}}=v_{\mathrm{A}}+\mathrm{m}\left(\mathrm{X}_{\mathrm{q}}\right) K_{\mathrm{A}}+p L_{\mathrm{A}} ; v_{\mathrm{d}}=v_{\mathrm{B}}+ \\
& \mathrm{m}\left(\mathrm{X}_{\mathrm{q}}\right) K_{\mathrm{B}}+p L_{\mathrm{B}} \\
& J_{\mathrm{ac}}=J_{\mathrm{AA}^{\prime} ;} J_{\mathrm{ab}}=J_{\mathrm{cd}}=J_{\mathrm{AB}} \\
& J_{\mathrm{bd}}=J_{\mathrm{BB}^{\prime}} ; J_{\mathrm{ad}}=J_{\mathrm{bc}}=J_{\mathrm{AB}^{\prime}}
\end{aligned}
$$

When $p=0$ and $\mathrm{m}\left(\mathrm{X}_{\mathrm{q}}\right)= \pm 3, \pm 2$, and \pm 1 , the transformations for the $a_{4}$ and $a^{\prime} b^{\prime} b^{\prime}$ sub-

* Some misprints occur in the invariants listed in Ref. 2. spectra of the $\mathrm{AA}^{\prime} \mathrm{A}^{\prime \prime} \mathrm{A}^{\prime \prime} \mathrm{X}_{\mathrm{n}} \mathrm{X}_{\mathrm{n}}{ }^{\prime}$ and $\mathrm{AA}^{\prime} \mathrm{BB}^{\prime}$ $\mathrm{X}_{\mathfrak{n}} \mathrm{X}_{\mathfrak{n}}^{\prime}$ systems, respectively, are obtained. Similarly, when $p=1$ and $m\left(\mathrm{X}_{\mathrm{q}}\right)= \pm 2$ and \pm 1 eqn. (9) gives the transformations for the $a a^{\prime} b^{\prime} b^{\prime}$ and abcd sub-spectra arising from the DDDDQD and DDDDST sub-states of the $\mathrm{AA}^{\prime} \mathrm{A}^{\prime \prime} \mathrm{A}^{\prime \prime} \mathrm{X}_{\mathrm{n}} \mathrm{X}_{\mathrm{n}}{ }^{\prime}$ and $\mathrm{AA}^{\prime} \mathrm{BB}^{\prime} \mathrm{X}_{\mathrm{n}} \mathrm{X}_{\mathrm{n}}{ }^{\prime}$ systems $(n=3$ or 2$)$.

The remaining recognizable energy level groupings not characterized by extreme values of $\mathrm{m}\left(\mathrm{X}_{\mathrm{q}}\right)$ are 1:2:4:2:1 $\left(A_{1}, B_{2}\right)+2: 2: 2\left(A_{2}, \mathrm{~B}_{1}\right)$ and 1:4:6:4:1 $(A, B)$ for the $\mathrm{AA}^{\prime} \mathrm{A}^{\prime \prime} \mathrm{A}^{\prime \prime} \mathrm{X}_{\mathrm{n}} \mathrm{X}_{\mathrm{n}}{ }^{\prime}$ and $\mathrm{AA}^{\prime} \mathrm{BB}^{\prime} \mathbf{X}_{\mathrm{n}} \mathrm{X}_{\mathrm{n}}{ }^{\prime}$ systems, respectively. Examination of these sub-patterns reveals that they cannot be identified with real $\mathrm{aa}^{\prime} \mathrm{bb}^{\prime}$ and abcd sub-spectra unless $J_{\mathrm{Xx}^{\prime}}=0$. This anomaly has been noted previously for similar systems containing a group of four chemically equivalent nuclei., ${ }^{1,4,9}$

For most problems of practical interest, however, it can be assumed that the long-range coupling constant $J_{\mathbf{x x}^{\prime}}$ is small or negligible. When $J_{\mathrm{XX}^{\prime}}=0$ the energy level groupings can be further reduced as shown in Table 2. In that case the $\mathrm{AA}^{\prime} \mathrm{BB}^{\prime}$ region of the $\mathrm{AA}^{\prime} \mathbf{B B}^{\prime} \mathbf{X}_{\mathbf{n}} \mathbf{X}_{\mathbf{n}}{ }^{\prime}$ system can be completely broken down into $(n+1)$ different $a a^{\prime} b^{\prime}$ sub-spectra and $\sum_{i=1}^{n} i$ different abcd sub-spectra. For the $\mathbf{A A}^{\prime} \mathrm{A}^{\prime \prime} \mathrm{A}^{\prime \prime \prime}$ $\mathrm{X}_{\mathrm{n}} \mathrm{X}_{\mathrm{n}}{ }^{\prime}$ system these sub-spectra simplify into $a_{4}$ and $a^{\prime} b^{\prime} b^{\prime}$ sub-spectra, respectively. The sub-spectral transformations are still given by eqn. (9) with the following expression of $p$ for the $\mathrm{QQ}, \mathrm{TT}, \mathrm{DD}$, and SS spin states:

$p=m-\left|\mathrm{m}\left(\mathrm{X}_{\mathrm{q}}\right)\right|$

where $m=F, F-2 \geq\left|\mathrm{m}\left(\mathrm{X}_{\mathrm{q}}\right)\right|$

In addition, the following values of $p$ are allowed for the asymmetrical ST and QD states: $p=\left|\mathrm{m}\left(\mathrm{X}_{4}\right)\right|$ for ST states and $p=1$ or 2 corresponding to even or odd values of $m\left(X_{6}\right)$, respectively, for QD states.

The transition frequencies of the general $\mathrm{aa}^{\prime} \mathrm{bb}^{\prime}$ ' system that can be obtained in analytical form are given in Table 3. The relevant spectral lines of a given sub-spectrum can then be found by inserting the appropriate expressions for the spectral parameters from eqn. (9).

The $X$ spectrum. The 1:1:1 $\left(A_{1}, A\right)+1\left(B_{2}, B\right)$ and 1:2:1 $\left(A_{1}, A_{2}, B_{1}, B_{2}\right)$ energy level groupings found in the DDDDDD sub-state of the $\mathrm{AA}^{\prime} \mathrm{A}^{\prime \prime} \mathrm{A}^{\prime \prime \prime} \mathrm{X}_{\mathrm{n}} \mathrm{X}_{\mathrm{n}}^{\prime}$ and $\mathrm{AA}^{\prime} \mathrm{BB}^{\prime} \mathrm{X}_{\mathrm{n}} \mathrm{X}_{\mathrm{n}}{ }^{\prime}$ systems

Acta Chem. Scand. A 28 (1974) No. 4 
Table 3. Closed-form transition frequencies for the $\mathbf{a} \mathbf{a}^{\prime} \mathrm{bb}^{\prime}$ spin system.

$\begin{array}{ll}\text { Line } & \text { Transition frequencies } \\ & \text { relative to } \frac{1}{2}\left(v_{\mathrm{a}}+\nu_{\mathrm{b}}\right) \cdot{ }^{a}\end{array}$

\begin{tabular}{ll}
$a_{1}$ or $b_{1}$ & $\mp \frac{1}{2} n \mp \frac{1}{2}\left[v_{\mathrm{ab}^{2}}+n^{2}\right]^{\frac{1}{2}}$ \\
$a_{2}$ or $b_{2}$ & $\mp \frac{1}{2} n \mp \frac{1}{2}\left[v_{\mathrm{ab}}{ }^{2}+n^{2}\right]^{\frac{1}{2}}$ \\
$a_{3}$ or $b_{3}$ & $\mp \frac{1}{2}\left[\left(v_{\mathrm{ab}}+m\right)^{2}+l^{2}\right]^{\frac{1}{2}} \mp \frac{1}{2}\left[m^{2}+l^{2}\right]^{\frac{1}{2}}$ \\
$a_{4}$ or $b_{4}$ & $\mp \frac{1}{2}\left[\left(v_{\mathrm{ab}}-m\right)^{2}+l^{2}\right]^{\frac{1}{2}} \mp \frac{1}{2}\left[m^{2}+l^{2}\right]^{\frac{1}{2}}$ \\
$a_{5}$ or $b_{5}$ & $\mp \frac{1}{2}\left[\left(v_{\mathrm{ab}}+m\right)^{2}+l^{2}\right]^{\frac{1}{2}} \pm \frac{1}{2}\left[m^{2}+l^{2}\right]^{\frac{1}{2}}$ \\
$a_{6}$ or $b_{6}$ & $\mp \frac{1}{2}\left[\left(v_{\mathrm{ab}}-m\right)^{2}+l^{2}\right]^{\frac{1}{2}} \pm \frac{1}{2}\left[m^{2}+l^{2}\right]^{\frac{1}{2}}$ \\
\hline
\end{tabular}

$a v_{\mathrm{ab}}=v_{\mathrm{a}}-v_{\mathrm{b}}, k=J_{\mathrm{aa}^{\prime}}+J_{\mathrm{bb}^{\prime}}, m=J_{\mathrm{aa}^{\prime}}-J_{\mathrm{bb}^{\prime}}, n=$ $J_{\mathrm{ab}}+J_{\mathrm{ab}^{\prime}}$ and $l=J_{\mathrm{ab}}-J_{\mathrm{ab}^{\prime}}$.

( $n=$ odd) can be identified with real $x_{2}$ and $x y$ sub-spectra. ${ }^{2} \mathrm{It}$ is not possible, however, to pick out known sub-spectra in the remaining sub- systems since these involve particles with spin $I>\frac{1}{2}$.

The energy level groupings characterized by $\mathrm{m}\left(\mathrm{A}_{4}\right)= \pm 2$ give rise to the familiar pair of lines located at $\nu_{\mathrm{X}} \pm 2 K_{\mathrm{A}}$ or $\nu_{\mathrm{X}} \pm\left(K_{\mathrm{A}}+K_{\mathrm{B}}\right)$ for the $\mathrm{AA}^{\prime} \mathrm{A}^{\prime \prime} \mathrm{A}^{\prime \prime} \mathrm{X}_{\mathrm{n}} \mathrm{X}_{\mathrm{n}}{ }^{\prime}$ and $\mathrm{AA}^{\prime} \mathrm{BB}^{\prime} \mathrm{X}_{\mathrm{n}} \mathrm{X}_{\mathrm{n}}{ }^{\prime}$ systems, respectively. Other sub-patterns, 1:2:3:2:1 and 1:2:3:4:3:2:1 under the $A_{1}, A_{2}, B_{1}$, and $B_{2}$ symmetry species for the $A^{\prime} A^{\prime \prime} A^{\prime \prime \prime} X_{n} X_{n}^{\prime}$ system for $n=2$ or 3 , respectively, resemble parts of $\mathrm{x}_{2} \mathrm{y}_{2}$ and $\mathrm{x}_{3} \mathrm{y}_{3}$ systems. However, because these sub-patterns are incomplete it seems unlikely that they have any significant meaning. Inspection of Table 2 indicates, however, that it may be possible to pick out groups of lines in these sub-patterns $\left[\mathrm{m}\left(\mathbf{A}_{\mathbf{4}}\right)= \pm 1\right]$ corresponding to real xy sub-spectra when $J_{\mathrm{xx}^{\prime}}=0$. Ten familiar 1:2:1 sub-patterns for $m\left(A_{4}\right)=0$

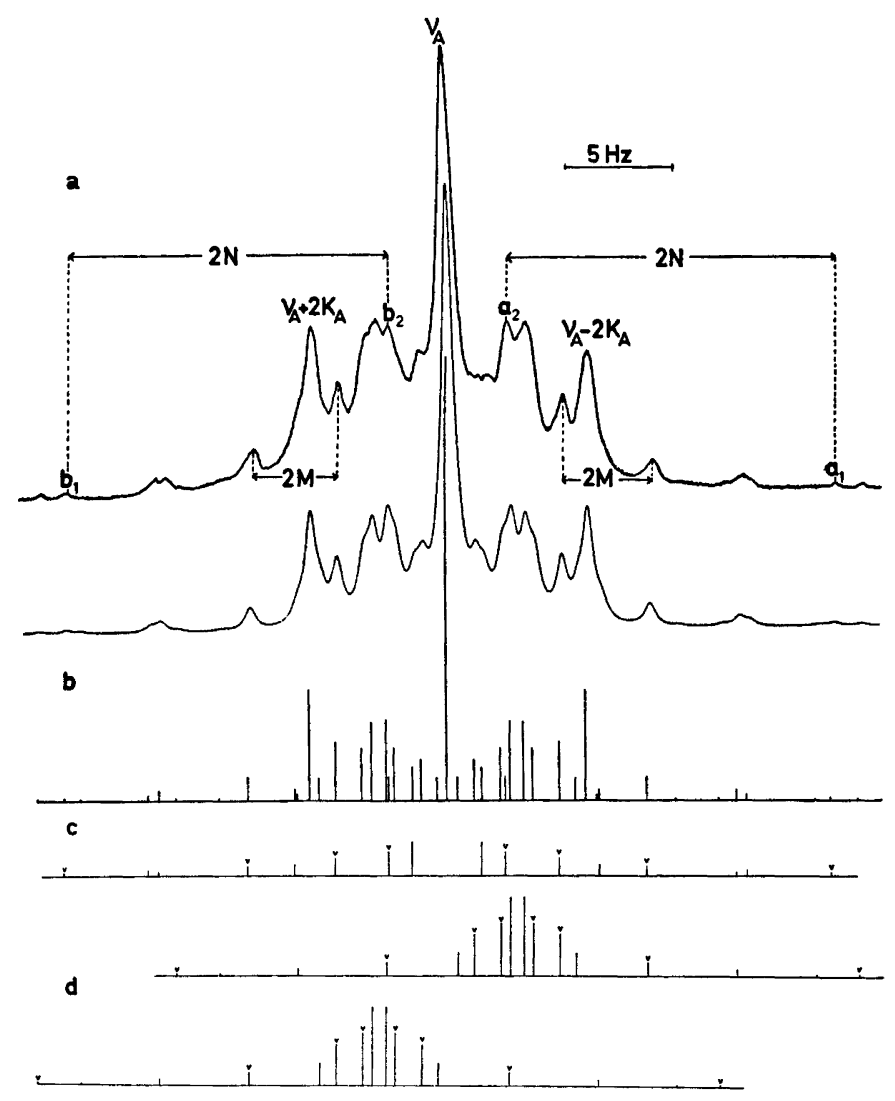

Fig. 1. The $100 \mathrm{MHz}$ methylene proton spectrum of 1,4-dibromobutane; $\mathrm{a}$ and $\mathrm{b}$, experimental and theoretical A spectrum; $c$ and d, the three $a^{\prime}{ }^{\prime} b^{\prime}$ sub-spectra based on eqn. (9) with $p=2, m\left(X_{4}\right)=0$ and $p=1, m\left(\mathrm{X}_{4}\right)= \pm 1$, respectively.

Acta Chem. Scand. A 28 (1974) No. 4 
and \pm 1 stand out in the DDDDDD state of the $\mathrm{AA}^{\prime} \mathrm{A}^{\prime \prime} \mathrm{A}^{\prime \prime} \mathrm{X}_{\mathrm{n}} \mathrm{X}_{\mathrm{n}}{ }^{\prime}$ system ( $\mathrm{n}=$ odd). ${ }^{2}$ These subpatterns constitute real xy sub-spectra even if $J_{\mathrm{XX}} \neq 0$. These xy sub-spectra are characterized by the following spectral parameters:

$v_{\mathrm{X}}=v_{\mathrm{X}}+\mathrm{m}_{(\mathrm{A}}\left(\mathrm{A}_{\mathbf{4}}\right)\left(K_{\mathrm{A}}-L_{\mathrm{A}}\right) ; v_{\mathrm{y}}=v_{\mathrm{X}}+$

$\mathrm{m}\left(\mathrm{A}_{\mathbf{a}}\right)\left(K_{\mathrm{A}}+L_{\mathrm{A}}\right)$

$J_{\mathrm{xy}}=J_{\mathrm{Xx}} \pm 2 N$ ( $A_{1}$ and $B_{2}$ species)

$J_{\mathrm{xy}}=J_{\mathrm{Xx}^{\prime}} \pm 2 M\left(A_{\mathrm{2}}\right.$ and $B_{1}$ species $)$

where $M=\frac{1}{2}\left(J_{\mathrm{AA}^{\prime \prime}}-J_{\mathrm{AA}^{\prime}}\right) ; N=\frac{1}{2}\left(J_{\mathrm{AA}^{\prime \prime}}+J_{\mathrm{AA}^{\prime}}\right)$

The positive and negative signs in the expression for $J_{\text {xy }}$ represent the $A_{1}, B_{1}$ and $A_{2}, B_{2}$ species, respectively. Once the relevant lines of these sub-systems have been identified $K_{\mathrm{A}}, L_{\mathrm{A}}, M$, $N$, and $J_{\mathrm{Xx}^{\prime}}$ can be found. The xy sub-spectra originating from the $1: 2: 3: 2: 1$ and $1: 2: 3: 4: 2: 1$ sub-patterns also follow from eqn. (11) by putting $J_{\mathbf{X X}^{\prime}}=0$.

\section{ILLUSTRATIVE EXAMPLES}

The $100 \mathrm{MHz}$ spectrum of 1,4-dibromobutane. This spectrum is of the $A A^{\prime} A^{\prime \prime} A^{\prime \prime} \mathbf{X}_{2} X_{2}$ ' type since the bromomethyl protons at each end of the molecule are magnetically equivalent. ${ }^{5}$ The experimental and theoretical spectra are shown in Figs. I and 2. The most prominent feature of the $A$ spectrum is the three strong lines at $v_{\mathrm{A}} \pm 2 K_{\mathrm{A}}$ and $v_{\mathrm{A}}$. The central line contributes 128 intensity units $\left(4 \mathrm{a}_{4}\right.$ sub-spectra) whereas the two remaining lines give rise to 32 intensity units each, ( $1 \mathbf{a}_{\mathbf{4}}$ sub-spectrum). The remaining part of the spectrum can be completely broken down into three $\mathbf{a a}^{\prime} \mathrm{bb}^{\prime}$ sub-spectra as shown in Fig. 1. The $a a^{\prime} b^{\prime} b^{\prime}$ transition lines that can be obtained on analytical form have been labelled (cf. Table 3).

Again the strong central line and the two lines at $\nu_{\mathrm{X}}+2 K_{\mathrm{A}}$ are the most outstanding features of the $\mathrm{X}$ spectrum. The line at $\nu_{\mathrm{X}}$ contributes

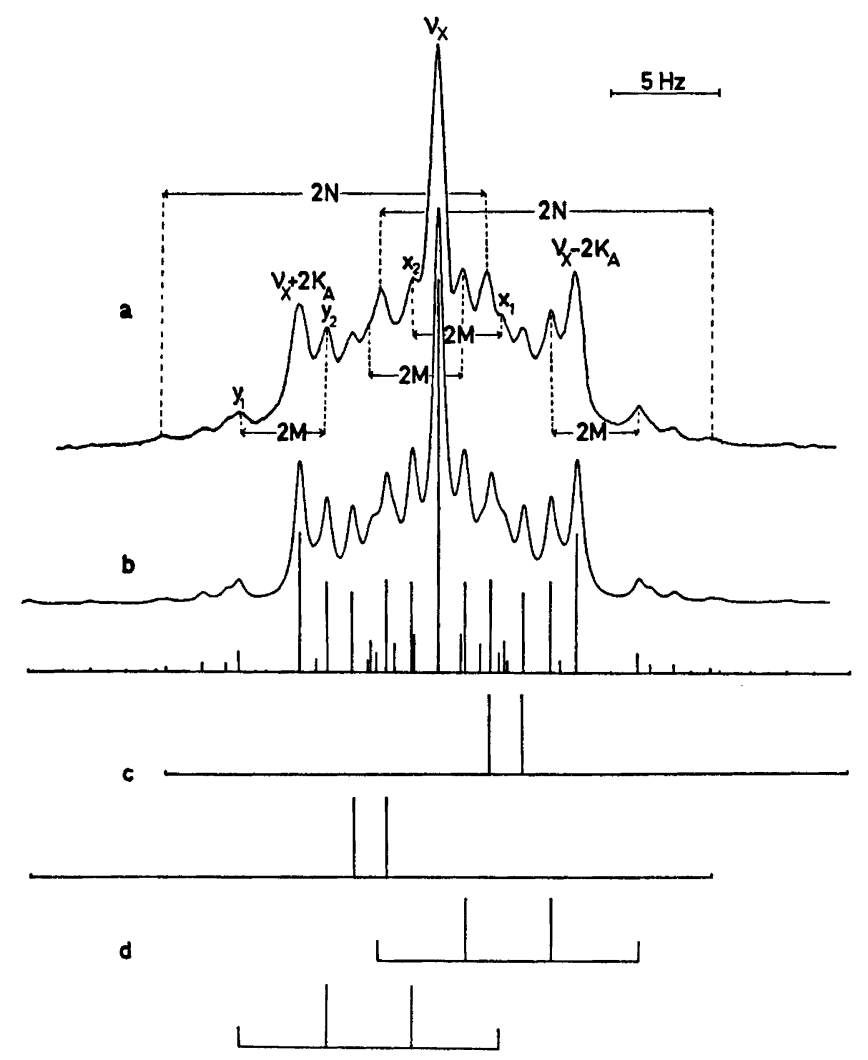

Fig. 2. The $100 \mathrm{MHz}$ bromomethyl proton spectrum of 1,4-dibromobutane; a and b, experimental and theoretical $X$ spectrum; $c$ and $d$, the four xy sub-spectra based on eqn. (11) with $m\left(A_{4}\right)= \pm 1$.

Acta Chem. Scand. A 28 (1974) No. 4 
about $22 \%$ to the total intensity of the $\mathrm{X}$ spectrum. The contributing xy. sub-spectra are also shown in Fig. 2.

Once the relevant spectral lines of the $a a^{\prime} \mathrm{bb}^{\prime}$ or xy sub-spectra have been picked out all spectral parameters of the $\mathrm{AA}^{\prime} \mathrm{A}^{\prime \prime} \mathrm{A}^{\prime \prime} \mathrm{X}_{2} \mathrm{X}_{2}^{\prime}$ system except $J_{\mathrm{AA}^{\prime \prime \prime}}$ and $L_{\mathrm{A}}$, can be obtained directly from the experimental spectrum as demonstrated in Figs. 1 and 2. $L_{\mathrm{A}}$ can be found indirectly by using eqn. (12).
$L_{\mathrm{A}}=\mathbb{t}\left[\left(b_{1}-a_{1}\right)\left(b_{2}-a_{2}\right)\right]^{\frac{1}{3}}=$ $\frac{1}{2}\left[\left(y_{1}-x_{1}\right)\left(y_{2}-x_{2}\right)\right]^{\frac{1}{2}}$

The relevant lines are indicated in Figs. 1 and 2. $J_{\mathrm{AA}^{\prime \prime \prime}}$ can only be found by diagonalizing $4 \times 4$ matrices. However, a precise value of $J_{\mathrm{AA}^{\prime \prime \prime}}$ is not obtainable from the A spectrum since $J_{\mathrm{AA}^{\prime \prime}}$ only affects weak combination transitions at the wings or lines near the strong peaks at $v_{\mathrm{A}}$ and $v_{\mathrm{A}} \pm 2 K_{\mathrm{A}}$. This follows from the fact that $L_{\mathrm{A}} \approx K_{\mathrm{A}}$ and $|k| \gg|l|$.

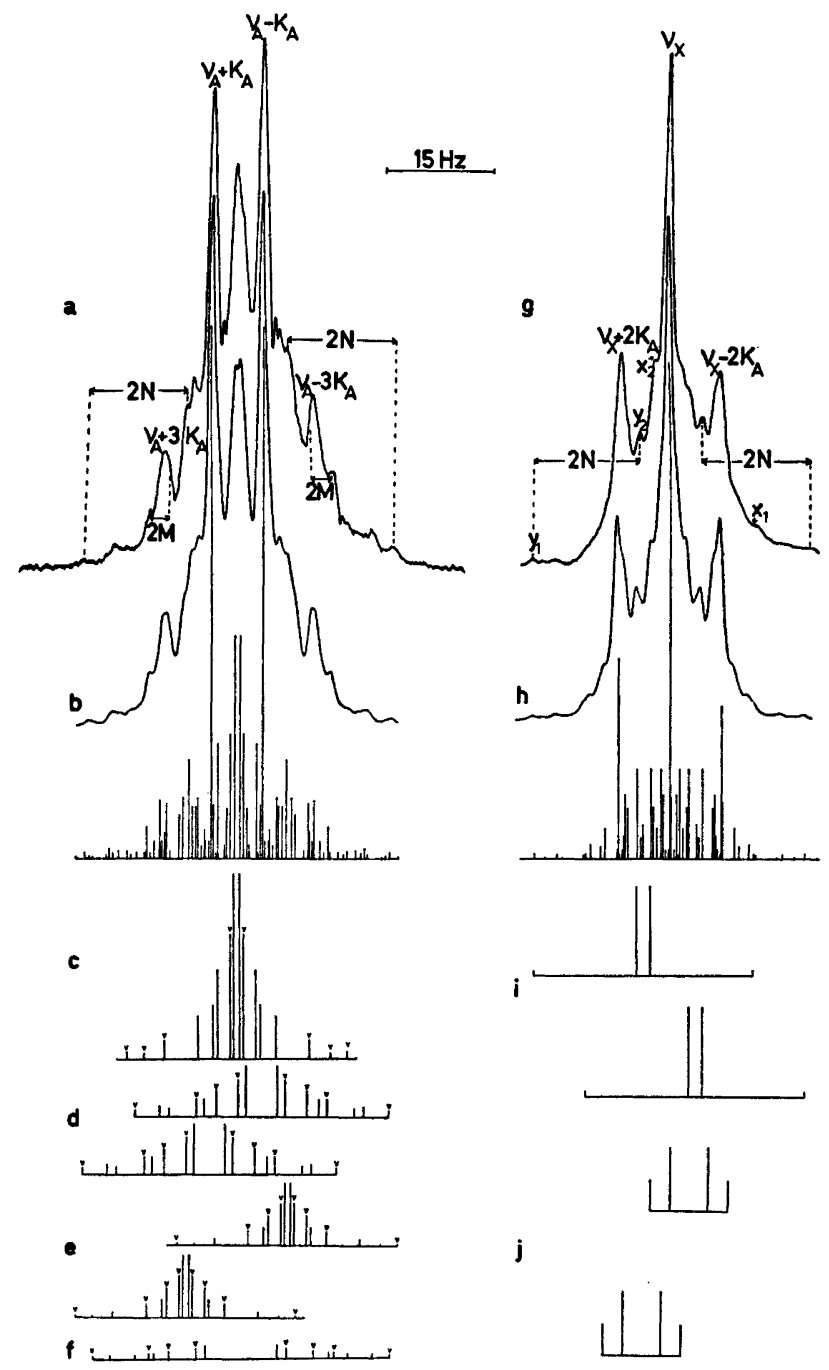

Fig. 3. The $270 \mathrm{MHz}$ spectrum of butane; $\mathrm{a}$ and $\mathrm{b}$, experimental and theoretical A spectrum; $\mathrm{c}-\mathrm{f}$, the six $a a^{\prime} \mathrm{bb}^{\prime}$ sub-spectra based on eqn. (9) with $\mathrm{c}, \mathrm{m}\left(\mathrm{X}_{6}\right)=0, p=1 ; \mathrm{d}, \mathrm{m}\left(\mathrm{X}_{6}\right)= \pm 1, p=2$; $e, m\left(X_{6}\right)= \pm 2, p=1 ; f, m\left(X_{6}\right)=0, p=3$. $g$ and $h$, experimental and theoretical $X$ spectrum; $i$ and $\mathrm{j}$, the four $\mathrm{xy}$ sub-spectra based on eqn. (11) with $m\left(A_{4}\right)= \pm 1$.

Acta Chem. Scand. A 28 (1974) No. 4 
The following averaged values of the spectral parameters (in $\mathrm{Hz}$ ) have been obtained directly from the experimental spectrum:

$v_{\mathrm{X}}-v_{\mathrm{A}}=144.62(144.52), K_{\mathrm{A}}=3.17$ (3.18),

$L_{\mathrm{A}}=3.43$ (3.43), $M=2.00(2.01), N=7.45$ (7.45). The excellent agreement with the values in the parentheses obtained from the iterative analysis, ${ }^{5}$ is noteworthy.

The signs of the two AX coupling constants can be determined relative to each other as $K_{\mathrm{A}}$ and $L_{\mathrm{A}}$ are found separately. The observed values of $M$ and $N$ show similarly that the cis and trans AA coupling constants have the same sign as expected.

The $270 \mathrm{MHz}$ spectrum of butane. This spectrum which is of the $\mathrm{AA}^{\prime} \mathrm{A}^{\prime \prime} \mathrm{A}^{\prime \prime} \mathrm{X}_{3} \mathrm{X}_{3}{ }^{\prime}$ type is shown in Fig. 3. The theoretical spectra have been calculated on basis of the $100 \mathrm{MHz}$ spectral parameters. ${ }^{10}$ The two strong lines at $v_{\mathrm{A}} \pm K_{\mathrm{A}}$ are the most outstanding feature of the A spectrum. Each line contributes 288 intensity units. The two lines at $v_{\mathrm{A}} \pm 3 K_{\mathrm{A}}$ contributing 32 intensity units each can also be seen. These four lines are also typical of the $\mathrm{AA}^{\prime} \mathbf{X}_{3} \mathrm{X}_{3}{ }^{\prime}$ system. ${ }^{1,3}$ The remaining part of the $A$ spectrum can be broken down into six different $\mathbf{a a}^{\prime} \mathbf{b b}^{\prime}$ subspectra (Fig. 3). The labelled lines indicate transitions that can be obtained in explicit form (cf. Table 3).

Since the chemical shift difference $v_{\mathrm{ab}}=-2 p L_{\mathrm{A}}$ it follows that all sub-spectra characterized by the same value of $p$ have identical appearance (cf. sub-spectra $\mathrm{c}$ and $\theta$ in Fig. 3).

The $\mathbf{X}$ spectrum resembles the corresponding spectrum of 1,4-dibromobutane in the sense that the four $x y$ sub-spectra and the three peaks located at $\nu_{\mathrm{X}}$ and $\nu_{\mathrm{X}} \pm 2 K_{\mathrm{A}}$ make a significant contribution to the total spectrum. This is a consequence of $J_{\mathrm{xx}^{\prime}}=0$. The central peak contributes ca. $20 \%$ to the total intensity of the $\mathrm{X}$ spectrum.

Again it is possible to obtain all spectral parameters except $J_{\mathrm{AA}}{ }^{\prime \prime}$ directly from the spectrum as indicated in Fig. 3. As for 1,4dibromobutane $L_{\mathrm{A}}$ may be obtained from the sub-spectra using eqn. (12). However, the rather

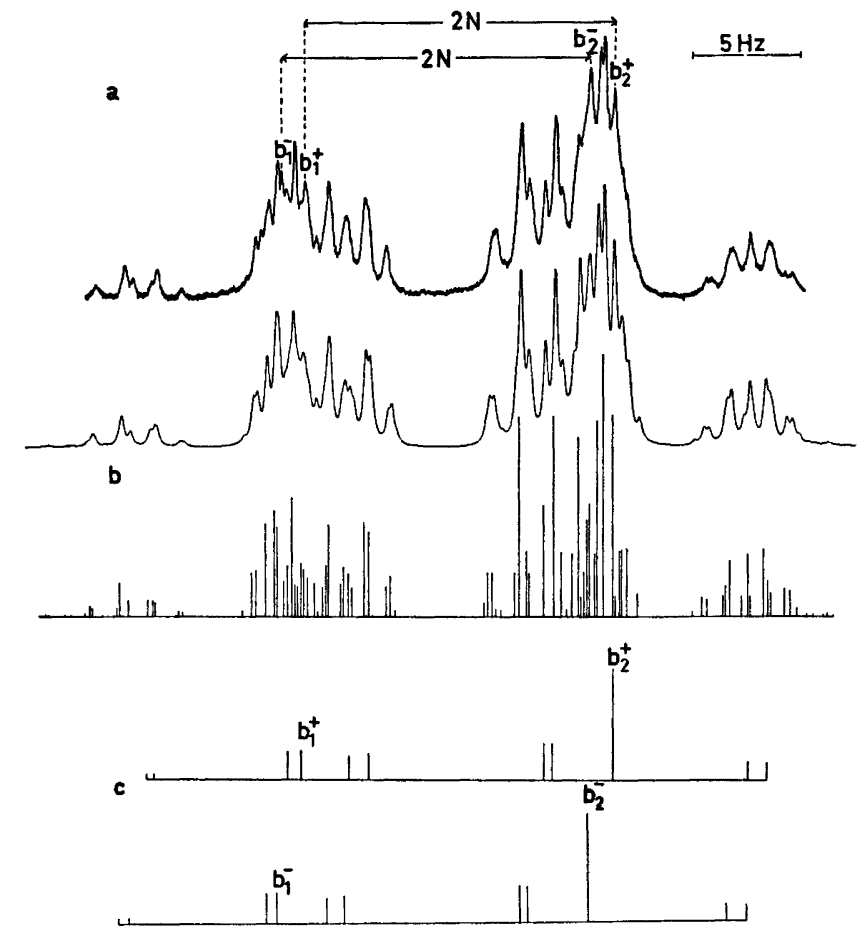

Fig. 4. The $100 \mathrm{MHz}$ spectrum of the diene protons at carbons 3 and 4 in trans, trans-2,4-hexadiene; $a$ and $b$, experimental and theoretical $B$ spectrum; $c$, the $B$ region of the $a a^{\prime} b^{\prime} b^{\prime}$ sub-spectra based on eqn. (9) with $p=0$ and $\mathrm{m}\left(\mathrm{X}_{6}\right)= \pm 1$. 
poor resolution and limited expansion of the experimental spectrum makes it impossible to measure precise values of $M$ and $L_{\mathrm{A}}$.

The observed values of $K_{\mathrm{A}}, L_{\mathrm{A}}, M$, and $N$ imply that the two AX coupling constants are of opposite sign whereas the cis and trans coupling constants have the same sign as for 1,4-dibromobutane.

The $100 \mathrm{MHz}$ spectrum of trans,trans-2,4hexadiene. The protons of this compound constitute an $\mathrm{AA}^{\prime} \mathrm{BB}^{\prime} \mathrm{X}_{3} \mathrm{X}_{3}{ }^{\prime}$ spin system (label $\mathrm{A}$ refers to the diene proton at the end of the molecule). The experimental and theoretical $B$ spectra are shown in Fig. 4. The $B$ region of the two $a a^{\prime} \mathrm{bb}^{\prime}$ sub-spectra arising from the DDDDDD sub-state are also displayed. Each of these sub-spectra contributes $4 \times 32=128$ intensity units and gives rise to prominent lines.

One can readily assign the intense $a_{1}, b_{1}, a_{2}$, and $b_{2}$ lines listed in Table 3. These lines can then be manipulated to find $N=\frac{1}{2}\left(J_{\mathrm{AB}}+J_{\mathrm{AB}^{\prime}}\right)$, $K_{\mathrm{A}}, K_{\mathrm{B}}$, and $v_{\mathrm{AB}}=v_{\mathrm{A}}-v_{\mathrm{B}}$ as shown in eqns. (13) $-(17)$.

$$
\begin{aligned}
& 2 N=a_{2}^{ \pm}-a_{1}^{ \pm}=b_{1} \pm-b_{2}^{ \pm} \\
& K_{\mathrm{A}}+K_{\mathrm{B}}=\frac{1}{2}\left[a_{2}^{+}-a_{2}^{-}+b_{2}^{+}-b_{2}^{-}\right] \\
& K_{\mathrm{A}}-K_{\mathrm{B}}=\frac{1}{2}\left[v_{\mathrm{ab}}{ }^{+}-v_{\mathrm{ab}}{ }^{-}\right] \\
& v_{\mathrm{AB}}=\frac{1}{2}\left[v_{\mathrm{ab}}+v_{\mathrm{ab}}^{-}\right]
\end{aligned}
$$

where $v_{\mathrm{ab}}^{ \pm}=-\left[\left(b_{1}^{ \pm}-a_{1}^{ \pm}\right)\left(b_{2}^{ \pm}-a_{2}^{ \pm}\right)\right]^{\frac{1}{2}}$

The + and - superscripts refer to the $\mathrm{aa}^{\prime} \mathrm{bb}^{\prime}$ sub-spectra characterized by $\mathrm{m}\left(\mathrm{X}_{6}\right)=1$ and -1 , respectively. $\quad M=\frac{1}{2}\left(J_{\mathrm{AB}}-J_{\mathrm{AB}^{\prime}}\right)$ and $G=\frac{1}{2}$ $\left(J_{\mathrm{AA}^{\prime}}-J_{\mathrm{BB}^{\prime}}\right)$ can be obtained from the $b_{4}$ and $b_{6}$ lines using a similar procedure. However, $H=\frac{1}{2}\left(J_{\mathrm{AA}^{\prime}}+J_{\mathrm{BB}^{\prime}}\right)$ can only be obtained by an indirect process involving trial and error fitting or else by iterative computer analysis.

The following averaged values (in $\mathrm{Hz}$ ) of the spectral parameters were obtained by using eqns. (13) $-(17)$ :

$v_{\mathrm{AB}}=-48.33, \quad K_{\mathrm{A}}=3.02, \quad K_{\mathrm{B}}=-0.64, \quad N=$ $7.12, M=7.85, G=9.23$.

$K_{\mathrm{A}}+K_{\mathrm{B}}$ also follows from the strong pair of lines at $v_{\mathrm{X}} \pm\left(K_{\mathrm{A}}+K_{\mathrm{B}}\right)$ in the $\mathrm{X}$ spectrum. The agreement with the refined values listed below is excellent. The theoretical spectra in Fig. 4 are based on the following parameters obtained from the iterative analysis:

Acta Chem. Scand. A 28 (1974) No. 4
$v_{\mathrm{AB}}=-48.90, K_{\mathrm{A}}=3.00, L_{\mathrm{A}}=3.25, K_{\mathrm{B}}=-0.64$, $L_{\mathrm{B}}=1.06, \quad N=7.12, \quad M=7.85, \quad G=9.47$ and $H=-10.83$.

The root-mean-square deviation was 0.095 for 582 matched lines in the whole spectrum. The calculated probable error for the parameters was $0.022 \mathrm{~Hz}$ or less. However, the real error in $K_{\mathrm{A}}$ and $L_{\mathrm{A}}$ is probably larger since it was difficult to make a unique assignment of some lines in the $\mathbf{A}$ and $\mathbf{X}$ spectra. Although the parameters above differ by less than $\pm 0.2 \mathrm{~Hz}$ from those reported by Albriktsen et al. ${ }^{7}$ the present data reproduce the experimental spectra far better.

The present work shows that the sub-spectral technique is a helpful aid in the analysis of large spin systems possessing some symmetry. Obviously, the more symmetry a system has the further the sub-spectral breakdown can be carried.

\section{NUMERICAL COMPUTATIONS}

The plots shown in Figs. 1-4 were generated by means of the UEANMR II, ${ }^{11}$ LAOCOON II, ${ }^{12}$ and KOMBIP ${ }^{13}$ computer programs.

The iterative fitting of the experimental and calculated spectra of trans,trans-2,4-hexadiene was performed by means of the UEAITR ${ }^{14}$ computer program. This program and its noniterative version UEANMR II make use of magnetic equivalence factoring based on the composite particle method, to reduce the size of the secular matrices.

The computations were performed on the UNIVAC 1110 computer at the University of Bergen. The graphical output was obtained on a Calcomp Plotter.

\section{EXPERIMENTAL}

trans, trans-2,4-Hexadiene and 1,4-dibromobutane were obtained from $K \& \mathrm{~K}$ laboratories and Fluka AG, respectively. These compounds were used without further purification. The synthesis of butane has been described in a previous paper. ${ }^{10}$ The neat liquids were introduced into $5 \mathrm{~mm}$ OD sample tubes and a small quantity of TMS was added to serve as locking and/or reference substance. About $25 \%$ $\mathrm{v} / \mathrm{v}$ of $\mathrm{CDCl}_{3}$ was used as D-lock signal source for the butane sample. The NMR tubes were degassed and sealed under vacuum.

The $100 \mathrm{MHz}$ and $270 \mathrm{MHz}$ spectra were run on VARIAN HA-100 and BRUKER HX-270 spectrometers, respectively, at ambient probe temperature $\left(c a .30^{\circ} \mathrm{C}\right)$. The frequency-calibrated 
spectra were recorded at $1 \mathrm{~Hz} / \mathrm{cm}$ and $3 \mathrm{~Hz} / \mathrm{cm}$ sweep widths. Line positions were obtained by averaging the results of 2 scans.

Acknowledgements. The author wishes to thank Mr. R. Bosvik at Bruker Spectrospin $\mathrm{AB}$, Sweden, for obtaining the $270 \mathrm{MHz}$ spectra of butane. The author is also indebted to cand. real. P. Albriktsen at the Chemical Institute, University of Bergen, Norway, for his assistance in recording the $100 \mathrm{MHz}$ spectra of trans,trans2,4-hexadiene.

\section{REFERENCES}

1. Diehl, P., Harris, R. K. and Jones, R. G.

- Progr. Nucl. Magn. Resonance Spectrosc. 3 (1967) 1 .

2. Diehl, P. Helv. Chim. Acta 48 (1965) 567.

3. Lynden-Bell, R. M. Mol. Phys. 6 (1963) 601.

4. Jones, R. G. NMR Basic Principles and Progress 1 (1969) 97.

5. Aksnes, D. W. Acta Chem. Scand. 26 (1972) 164.

6. Ayanbadejo, F. A. M. Spectrochim. Acta 25.4 (1969) 1009.

7. Albriktsen, P., Cunliffe, A. V. and Harris, R. K. J. Magn. Resonance 2 (1970) 150.

8. Emsley, J. W., Feeney, J. and Sutcliffe, L. H. High Resolution Nuclear Magnetic Resonance Spectroscopy, Pergamon, New York 1965, Vol. 1.

9. Jones, R. G. and Walker, S. M. Mol. Phys. 10 (1966) 349, 363.

10. Aksnes, D. W. and Albriktsen, P. Acta Chem. Scand. 26 (1972) 3021.

11. Woodman, C. M. Personal communication.

12. Castellano, S. and Bothner-By, A. A. $J$. Chem. Phys. 41 (1964) 3863.

13. Aksnes, D. W. KOMBIP, Quantum Chemistry Program Exchange, Chemistry Department, Indiana, U.S.A., Program No. 205.

14. Johannesen, R. B., Ferretti, J. A. and Harris, R. K. J. Magn. Resonance 3 (1970) 84.

15. Kaiser, R. J. Magn. Resonance 1 (1969) 534.

Received November 13, 1973. 